\title{
Behavioural responses to human skin extracts and antennal phenotypes of sylvatic first filial generation and long rearing laboratory colony Rhodnius prolixus
}

\author{
Mario Iván Ortiz, Alejandro Suárez-Rivillas, Jorge Molina/ ${ }^{+}$ \\ Departamento de Ciencias Biológicas, Centro de Investigaciones en Microbiología y Parasitología Tropical, \\ Facultad de Ciencias, Universidad de los Andes, AA 4976 Carrera 1E, 18A-10 Bogotá, Colombia
}

Chagas disease is a major public health issue and is mainly spread by Triatominae insects (Hemiptera: Reduviidae). Rhodnius prolixus is the main vector species in Northern South America. Host-seeking behaviour in R. prolixus is mediated by different compounds that are produced by and emanate from the host or microbiota on the host's skin. We tested the behavioural responses of sylvatic first filial generation (FI) and colony insects to extracts of human skin with a dual choice olfactometer. In addition, we compared the antennal phenotypes in both populations. No statistical differences were found between the two populations at the behavioural level. Both showed a preference for face and feet extracts and this effect was abolished for face extracts after treatment with an antibacterial gel. The observation of the antennal phenotype showed that there were differences between both groups in the total length, total surface area and number and density of bristles. However, the number and density of chemoreceptive sensilla (basiconic and thin and thick-walled trichoids) and the total density of sensilla did not show statistically significant differences. These results demonstrate that colony insects, which have only been fed with living hens for the last 30 years, are attracted by human skin extracts in a similar way as F1 sylvatic insects.

Key words: Rhodnius prolixus - Chagas disease - skin odours - chemoreception - bacteria - antennal sensilla

Chagas disease is a systemic chronic parasitic infection caused by Trypanosoma cruzi and represents a health concern for 28 million people in Latin America. According to recent data collected from 21 endemic countries, the number of new cases each year due to vector transmission is 41,200 (TDR 2009).

Vectors of $T$. cruzi belong to the subfamily Triatominae (Hemiptera: Reduviidae), of which 140 species have been described (Schofield \& Galvao 2009). Seventy-two species of triatomines have been reported to be naturally infected with T. cruzi (Carcavallo et al. 1998), but only few of them are considered primary vectors, including Triatoma infestans (Klug, 1834), Triatoma dimidiata (Latreille, 1811) and Rhodnius prolixus (Stål, 1859) (Moncayo \& Ortiz 2006).

In Colombia, $R$. prolixus is considered to have the highest vectorial capacity due to its geographical distribution, adaptation to human dwellings and presence in sylvatic environments, especially palm trees (Guhl et al. 2007, López et al. 2007).

Host-seeking behaviour in $R$. prolixus is influenced by different volatile compounds present in human odour (Guerenstein \& Lazzari 2009). Recently, preliminary evidence has shown the possible role of bacteria on human skin in biting preference for different body parts in $R$. prolixus adults (Ortiz \& Molina 2010).

Financial support: Colciencias (1204-459-21479)

+ Corresponding author: jmolina@uniandes.edu.co

Received 15 December 2010

Accepted 6 June 2011
Volatile compounds are detected by olfactory protein receptors on bipolar neurons inside the cuticular sensilla on the antennae of triatomines and other insects (Mayer 1968, Catalá 1998, Leal 2005, Guerenstein \& Lazzari 2009). Antennal sensilla in triatomines are also involved in mechanoreception, proprioception and thermo-hygroreception (Catalá 1997, 1998).

Sensilla located on the rostrum of triatomines can be excluded as potential receptors of volatile compounds because they are involved in mechanoreception, proprioception, thermo-hygroreception and contact chemoreception (Catalá 1996). In addition, backfills from the rostrum of triatomines showed fibres that converge into the subesophageal ganglion, but not in the antennal lobes (Barrozo et al. 2009).

Four types of antennal sensilla have been frequently described in different studies of triatomines: mechanoreceptor-like bristles (BRs), chemoreceptor-like thinwalled trichoids (THs), thick-walled trichoids (TKs) and basiconics (BAs) (Fig. 1) (Catalá \& Schofield 1994, Catalá 1997, Gracco \& Catalá 2000, Carbajal de la Fuente \& Catalá 2002, Catalá et al. 2004, Esteban et al. 2005, Villela et al. 2005).

Some triatomine species are easily reared and maintained in laboratory conditions (Pennington et al. 2005) and have been maintained under these artificial conditions for several years. Changes in antennal phenotypes (number, type and distribution of sensilla) associated with laboratory rearing have been reported for $T$. infestans, $R$. prolixus and Rhodnius pallescens (Catalá et al. 2004). In addition, changes in antennal patterns have been reported for $T$. dimidiata captured from sylvatic, peridomestic and domestic habitats (Arroyo et al. 2007). 
Both results suggest that artificial rearing and development of individuals of the same species under different ecosystem conditions can lead to modifications in the sensory array to allow adaption to the sensorial requirements of different habitats (Catalá 1997).

To our knowledge, an attempt to correlate the results from behavioural and morphological analyses of antennal chemoreception of triatomines has not been performed. We thus behaviourally evaluated attraction to human skin extracts of $R$. prolixus reared under laboratory conditions and fed with living hens for 30 years, and we compared these results with the attraction to the same extracts of the first filial generation (F1) of $R$. prolixus recently captured from palm trees. Finally, we studied the antennal phenotypes of both populations of $R$. prolixus and correlated them with the previously obtained behavioural information.

\section{SUBJECTS, MATERIALS AND METHODS}

Insects - Colony and F1 sylvatic male and female $R$. prolixus with an average weight of $0.0381 \mathrm{~g}$ (after approximately 15 days of starvation) were used in the experiments. The colony insects were captured from wild populations in San Juan de Arama, Department of Meta, and have been reared in our laboratory since 1979. For the past 30 years, no wild individuals have been introduced into the rearing jars.

Sylvatic insects were captured with hen-bait adhesive traps from eight palm trees in El Viso $\left(5^{\circ} 00^{\prime} 10^{\prime \prime} \mathrm{N}\right.$ $72^{\circ} 42^{\prime} 25^{\prime \prime} \mathrm{W}$ ) (Municipality of Mani, Department of Casanare) in March 2009. Taxonomic identification with morphological criteria of sylvatic triatomines was performed following the keys of Lent and Wygodzinsky (1979). For the experiments, only F1 adult sylvatic bugs obtained from an initial population of 87 nymphs of different instars were used. Blood sources for the triatomines found by our group on palm trees in Casanare included different species of rodents, bats, opossums, anteaters, birds, reptiles and amphibians.

Both populations of insects were maintained at 27 $\pm 2^{\circ} \mathrm{C}$ and $75 \pm 10 \%$ relative humidity with an artificial 6:00 am-18:00 pm light/dark illumination regime and

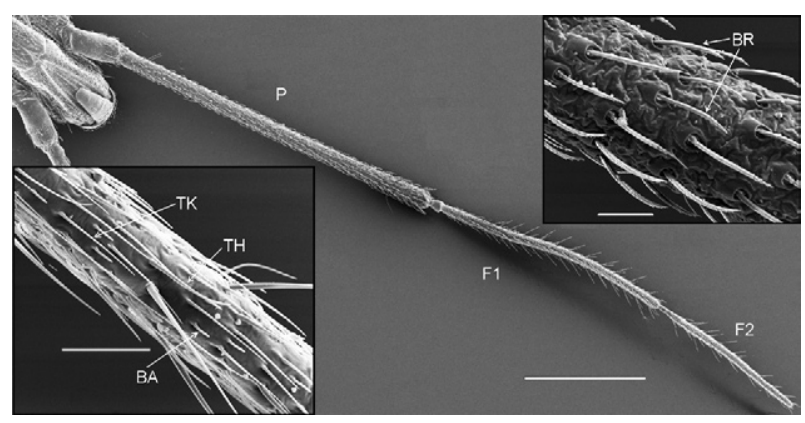

Fig. 1: female head from laboratory colony (ventral view). Scanning electron micrograph showing the antennae of an adult of Rhodnius prolixus. Antennal segments: pedicel (P), flagelar segment (F1) and $\mathrm{F} 2$. Bar $=1 \mathrm{~mm}$. Inserts show the four types of sensilla: thin-walled trichoids (TH), thick-walled trichoids (TK), basiconics (BA) and bristles (BR). Bars $=50 \mu \mathrm{m}$. fed monthly on hens. Colony and F1 sylvatic adults of $R$. prolixus were reared in jars with a volume of $4.5 \mathrm{~L}$. Colony insects were obtained from a jar with 350 adults and 8,053 nymphs, while F1 sylvatic insects were in a jar with 25 adults and 575 nymphs.

Olfactometer - All experiments were conducted in an olfactometer that consisted of dark polyvinyl chloride material tubes (wall width of $2 \mathrm{~mm}$ and diameter of $1.23 \mathrm{~cm}$ ) for the "T" arms and two hermetic polystyrene transparent containers were coupled to both olfactometer ends for stimulus delivery (Ortiz \& Molina 2010).

An air pump coupled to both stimulus containers delivered a constant and regular charcoal-filtered airstream at $<10 \mathrm{~cm} / \mathrm{s}$ measured with a thermo-anemometer (45118, EXTECH Instruments) in both stimulus containers. Each insect was tested individually. Between each individual evaluation, the orientation of the olfactometer was changed. After the evaluation of one specific stimulus (every 20 insects), the olfactometer was changed to a new one that had been washed at least three times with water and gel soap and rinsed with water to completely eliminate the soap. The position of the stimulus was also changed after testing 20 insects (Ortiz \& Molina 2010).

Stimuli - Ortiz and Molina (2010) obtained human skin extracts by rubbing the face, hands or feet of volunteers for $20 \mathrm{~s}$ with a $1.5 \mathrm{~cm} \times 1.5 \mathrm{~cm}$ filter paper (Whatman paper 5) with $50 \mu \mathrm{L}$ of n-hexane $(99 \% \mathrm{pu}-$ rity, Chemie) (Nicolaides 1974). Here, we used the same procedure with more volunteers ( 3 women and 2 men) to avoid pseudo replication and to compare responses among different volunteer extracts.

Face extracts of individuals previously treated with an anti-bacterial and odourless gel (Bactroderm ${ }^{\circledR}$ ) containing the naturally occurring broad spectrum antibiotic mupirocin $\{(9-4-[5 \mathrm{~S}-(2 \mathrm{~S}, 3 \mathrm{~S}-$ epoxy-5S-hydroxy-4Smethylhexyl)-3R,4R-dihydroxy tetrahydropyran-2S-yl]-3methylbut-2(E)-enoyloxy-nonanoic acid\} and the antiseptic Triclosan [5-cloro-2-(2,4-diclorofenoxi)fenol] were also tested. This gel was applied topically for $20 \mathrm{~s}$ on all face areas (except eyes) in the five volunteers for $15 \mathrm{~min}, 1 \mathrm{~h}$ and $24 \mathrm{~h}$ before rubbing.

Behavioural experiments - The behavioural experiments with 600 adult insects from the colony and $600 \mathrm{~F} 1$ adults from sylvatic environments followed the same procedures used by Ortiz and Molina (2010). All experiments were conducted in a room with low intensity light (average light intensity of $0.3 \mu \mathrm{w} / \mathrm{cm}^{2}$ measured with a radiometer/ photometer ILT1400A, International Light Technologies Inc) at $24 \pm 2^{\circ} \mathrm{C}$ between 18:00 am-19:30 pm local time.

An airflow with stimulus (human skin extracts) was applied immediately before each individual insect was introduced into the large arm of the "T". A maximum of 5 min was given for each bug to choose a container (1 trial). The response (human skin extract container vs. clean container) of each adult was then recorded and the insect was removed to perform the next trial. This procedure was repeated each time with a different insect until 20 trials were completed (1 experiment). In all cases, each individual insect was tested only once and 
insects were not allowed to accumulate in any container. Ten males and 10 females were tested individually and randomly in each experiment.

Previous behavioural experiments have shown that anti-bacterial gel or n-hexane do not affect $R$. prolixus responses (Ortiz \& Molina 2010).

Antennal phenotype - An optical microscope was used to determine the antennal phenotypes of F1 sylvatic and colony insects. Four types of sensilla were studied: THs, TKs, BAs and BRs (Catalá \& Schofield 1994, Catalá 1997).

Ten colony and $10 \mathrm{~F} 1$ sylvatic adults (5 females and 5 males from each group) were sacrificed at $-20^{\circ} \mathrm{C}$ for $10 \mathrm{~min}$ and their heads were removed under a stereoscope (Nikon SMZ 1500). The heads were cleaned with distilled water (twice for $10 \mathrm{~min}$ ), cleared in 4\% potassium hydroxide for $24 \mathrm{~h}$ and neutralised with $5 \%$ acetic acid for $60 \mathrm{~min}$. One antenna from each insect was cut at the level of the scape and slide-mounted with glycerin. Collapsed antennae were excluded.

The distribution of the four types of sensilla over the whole ventral surface of the three distal segments of the antenna [pedicel (P), F1 and F2] (Fig. 1) was determined by optical microscopy at $400 \mathrm{X}$ magnification (Nikon Optiphot-2).

The density of antennal sensilla was calculated by dividing the number of sensilla by the ventral area. The ventral area of the antenna was determined by measuring the total length and the width at the midpoint of the length of each antennal segment with a calibrated micrometer.

In addition, scanning electron microscopy (SEM) was used. Two heads of colony and two heads of F1 sylvatic adults ( 1 female and 1 male from each group) were cut at the level of the neck and laid with the ventral side up on a SEM stub. Each individual preparation was coated with gold for $1 \mathrm{~h}$ in a sputter coater (Dentom Vacuum Desk IV) and photographed at $300 \mathrm{X}$ and $800 \mathrm{X}$ with a SEM (JEOL JSM 6490-LV) at $10 \mathrm{kV}$ or $20 \mathrm{kV}$. The pictures obtained by SEM were used to corroborate the morphology of the antennal sensilla obtained with optical microscopy.

Data analysis - Data from each experimental series were analysed using a binomial test (Zar 1999).

Comparisons between the numbers of insects (colony and F1 sylvatic) attracted to each stimulus (face, hand, feet and face treated with gel) were compared by means of Mann-Whitney tests (non-parametric test used to compare medians) after non-normal distribution of the data was evaluated by Kolmogorov-Smirnov tests ( $p<$ 0.05 ). The comparisons between the numbers of insects attracted to the extracts from each of the volunteers were made by means of the Fisher's exact test of proportion for independent samples. Differences between the responses of males and females to each of the stimuli were compared by means of goodness of fit Chi-square tests.

The antenna size, density and number of antennal sensilla data from colony and F1 sylvatic insects were analysed by means of Shapiro tests (normality test), F tests (variances homogeneity) and t tests (mean comparison) using the software R: A Language and Environment for Statistical Computing (R Development Core Team 2006).

\section{RESULTS}

Behavioural experiments - As previously shown by Ortiz and Molina (2010), no statistically significant differences in attraction to human skin extracts between male and female insects were observed (Chi-square $=$ $2.15, \mathrm{p}>0.1$ colony insects, Chi-square ${ }_{(1)}=2.11, \mathrm{p}>0.1$ F1 sylvatic insects). Further analyses will be conducted without considering the sex of the triatomines tested.

Behavioural experiments between colony and F1 sylvatic bugs showed no statistically significant differences in the number of insects attracted to each of the five extracts of volunteers in each of the stimuli tested (face, hands and feet) (Fisher's exact test of proportion for independent samples, n.s.). However, face and feet extracts from all five volunteers were more attractive than hand extracts in both populations of insects tested (Mann-Whitney test, $\mathrm{p}<0.05$ ) (Fig. 2).

These results suggest that the attraction to human skin volatiles in both populations tested were the same. In fact, the number of insects from each population attracted to each extract showed no statistically significant differences (Mann-Whitney test, $\mathrm{p}>0.05$ ).

We found that attraction to face extracts was eliminated after an antibacterial gel was applied for at least $1 \mathrm{~h}$ before the tests on both colony and F1 sylvatic insects (binomial test, $\mathrm{p}>0.05$ ) (Fig. 3).

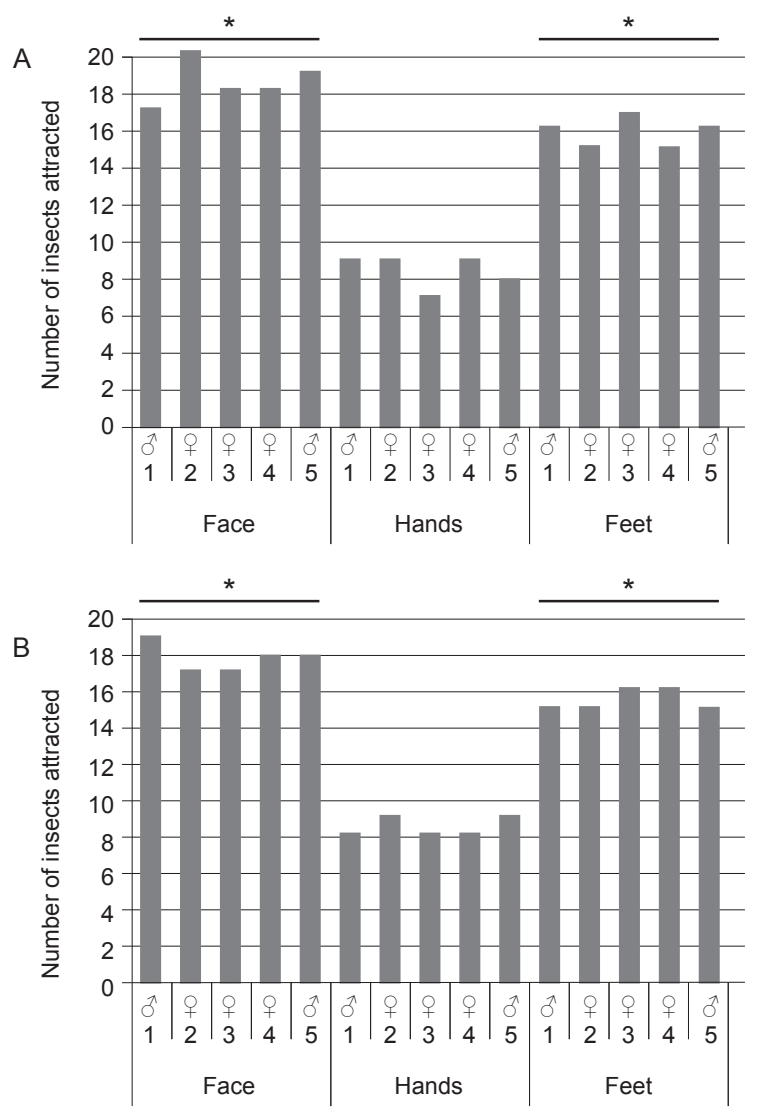

Fig. 2: total number of flagelar segment (F1) sylvatic (A) and colony (B) adults of Rhodnius prolixus attracted to different human skin extracts (face, hands and feet) from five volunteers ( 2 men and 3 women). Asterisks mean statistically significant differences $(\mathrm{p}<0.05)$. 

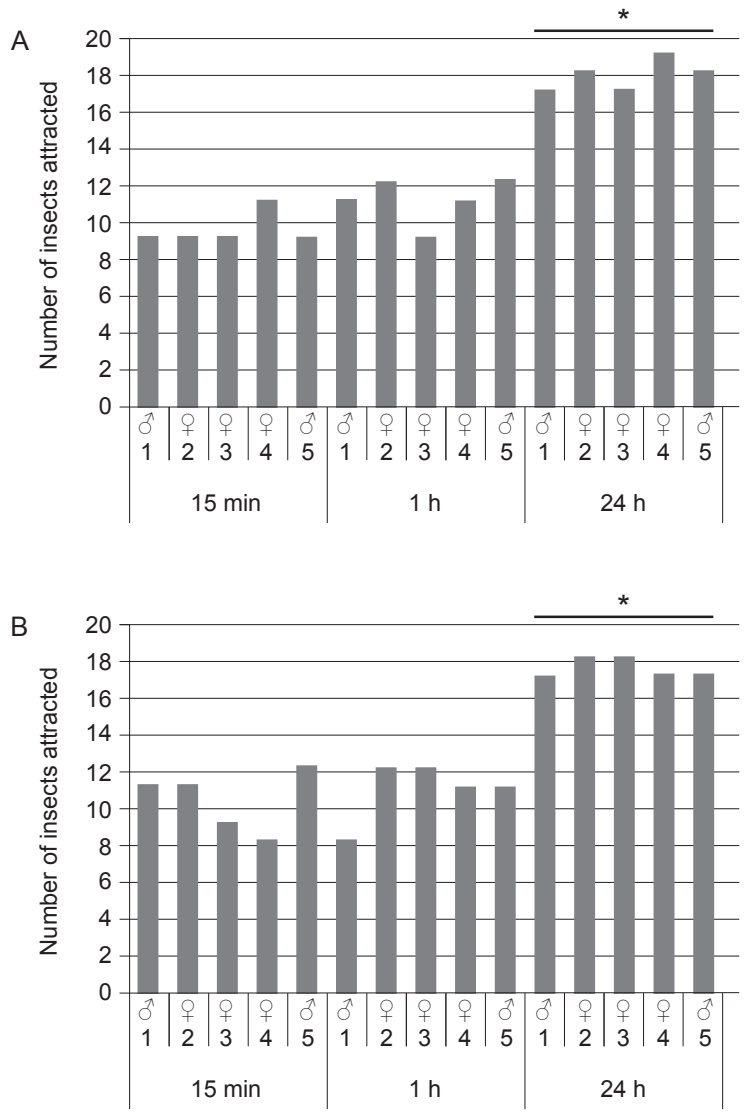

Fig. 3: total number of flagelar segment (F1) sylvatic (A) and colony (B) adults of Rhodnius prolixus attracted to face skin extracts from five volunteers ( 2 men and 3 women) $15 \mathrm{~min}, 1 \mathrm{~h}$ and $24 \mathrm{~h}$ after treatment with anti-bacterial gel. Asterisks mean statistically significant differences $(\mathrm{p}<0.05)$.

Antennal phenotype - Because there were no behavioural differences between colony and F1 sylvatic insects, we were interested in morphological comparisons at the level of the antennae. The following analysis of the antennal phenotype encompasses only the data obtained with an optical microscope because there were no differences in the identification of the four types of antennal sensilla using both types of microscopes.

The distribution of antennal sensilla in F1 sylvatic and colony $R$. prolixus showed that BR sensilla were confined mostly to the $\mathrm{P}$, while TH, TK and BA sensilla were present only on the two flagellar segments.

A comparison of the total length of the antennae of both populations showed that the antennae of F1 sylvatic $R$. prolixus were statistically longer than the antennae of colony triatomines. The $\mathrm{P}$ was the antennal segment that contributed most to the length difference. As expected, statistically significant differences in the total ventral surface area were also observed between the two triatomine populations (Table).

Comparison of the total density of the four different types of sensilla (TK, TH, BA and BR) showed no statistically significant differences between F1 sylvatic and colony insects ( $t$ test, n.s.) (Fig. 4A). However, when each type of sensilla was considered individually, the total density of BRs in F1 sylvatic insects was significantly higher than that in colony insects $(t$ test, $\mathrm{p}=0.03844)$ (Fig. 4A).

The same result was obtained for an analysis of the total number of sensilla. In this case, the four different types of sensilla showed no statistically significant differences ( $t$ test, n.s.) (Fig. 4B). However, when each type of sensilla was considered individually, the number of BRs was significantly larger in F1 sylvatic insects than in colony insects ( $t$ test, $\mathrm{p}=0.00004459)$ (Fig. 4B).

\section{DISCUSSION}

The attraction of colony and F1 sylvatic $R$. prolixus to human skin extracts was generally the same and independent of the volunteers and time of rearing under artificial conditions (Figs 2,3). The higher attraction to face and feet extracts previously reported by Ortiz and Molina (2010) was confirmed here with a larger number of triatomines and volunteers (Fig. 2). These results emphasised the idea that the biting behaviour of R. prolixus, similarly to Anopheles gambiae (Takken \& Knols 1999, Enserink 2002, Verhulst et al. 2009), is not a random process and is clearly influenced by the bacteria present on the skin. The importance of the Rhodnius-bacteriahuman face interaction was confirmed here for Chagas disease transmission (Figs 2, 3).

Species of Triatominae reared under controlled laboratory conditions tend to show a reduction in size relative to the original sylvatic populations (Dujardin et al. 1999, Jaramillo et al. 2002). According to Dujardin (1998), a reduction in body size may reflect the high density of populations in rearing jars and the limited supply of blood meal.

Sensilla on the antennae of $R$. prolixus from Colombia also have been shown to be sensitive to the population density (Catalá et al. 2004). We found that F1 sylvatic insects reared under low densities have larger antennae, more BR sensilla and a similar number of chemoreceptive sensilla (TH, TK and BA) (Catalá 1997, 1998) compared with colony insects (Fig. 4B). A reduction in BR sensilla could be due also to differences in the geographic origin of the two populations as suggested by Esteban et al. (2005).

The similarity in the number of chemoreceptive sensilla support the responses obtained with our behavioural experiments with an olfactometer (Fig. 2). We expect that equal numbers in antennal sensilla should produce equal numbers of neurons involved in stimulus reception. However, it is important to mention that sensilla physiology could be different despite the similar numbers of sensilla (Altner \& Prillinger 1980). Future electrophysiological recordings in single chemoreceptive antennal sensilla would help to clarify this issue.

How can a reduction in antennal size without a change of the number of chemo-sensitive sensilla be explained (Fig. 4B)? We observed that colony R. prolixus mainly display a reduction in the length of the $\mathrm{P}(t$ test, $\mathrm{p}$ $=0.0000405)$. Similar numbers of chemoreceptive sensilla in both populations ( $t$ test, n.s.) (Fig. 4B) are then expected as we assume that these sensilla are located on the F1 and F2 antennal segments in Rhodninii. 
TABLE

Average values and standard deviation in antennal segments comparing flagelar segment (F1) sylvatic and colony Rhodnius prolixus in length and area parameters

\begin{tabular}{lccc}
\hline & & & Significance \\
& F1 sylvatic & Colony & 0.0002761 \\
\hline Total antennal length $(\mathrm{mm})$ & $9.09 \pm 0.19$ & $8.34 \pm 0.33$ & 0.0000405 \\
Pedicel length $(\mathrm{mm})$ & $4.14 \pm 0.27$ & $3.63 \pm 0.17$ & 0.0012 \\
F1 length $(\mathrm{mm})$ & $2.93 \pm 0.10$ & $2.71 \pm 0.12$ & 0.1435 \\
F2 length $(\mathrm{mm})$ & $2.02 \pm 0.17$ & $1.95 \pm 0.10$ & 0.02334 \\
Total antennal area $\left(\mathrm{mm}^{2}\right)$ & $1.15 \pm 0.10$ & $1.06 \pm 0.06$ & 0.04188 \\
Pedicel area $\left(\mathrm{mm}^{2}\right)$ & $0.66 \pm 0.08$ & $0.61 \pm 0.04$ & 0.01281 \\
F1 area $\left(\mathrm{mm}^{2}\right)$ & $0.3165 \pm 0.02$ & $0.28 \pm 0.01$ & 0.6451 \\
F2 area $\left(\mathrm{mm}^{2}\right)$ & $0.1657 \pm 0.02$ & $0.17 \pm 0.01$ & \\
\hline
\end{tabular}

A
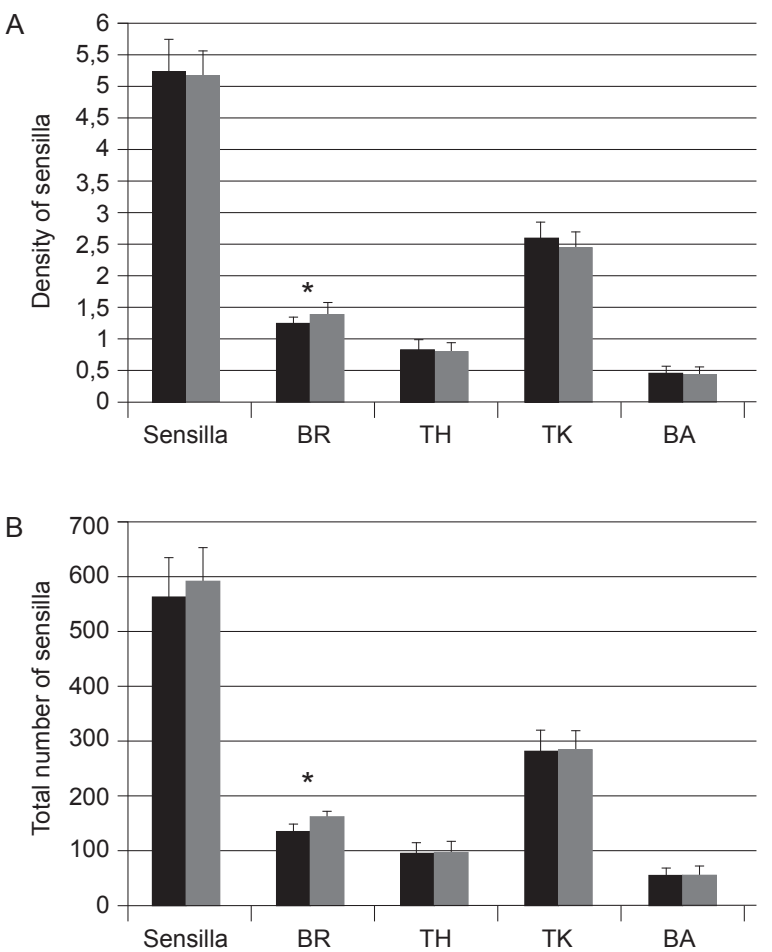

Fig. 4: antennal sensilla in Rhodnius prolixus from colony (black) and F1 sylvatic (gray). A: bar plot showing relative densities of sensilla types. Y-axis is number of sensilla per $10.000 \mu \mathrm{m}^{2}$ of surface area and standard deviation; B: bar plot showing average number of sensilla types and standard deviation; BA: basiconics; BR: bristles; TH: thinwalled trichoids; TK: thick-walled trichoids. Asterisks mean statistically significant differences $(\mathrm{p}<0.05)$.

Results obtained in Anopheles showed that Anopheles quadriannulatus (zoophilic) had a larger antenna with a greater number of chemoreceptive sensilla than $\operatorname{did}$ A. gambiae (highly anthropophilic) (Pitts \& Zwiebel 2006). The host preferences of different Anopheles species may be reflected in the numbers of olfactory cells that respond to different odours and/or in the sensitivities of these cells (van den Broek \& den Otter 1999).
Results in Anopheles suggest that, to maintain its euryphagic behaviour (Zeledón \& Rabinovich 1981), colony $R$. prolixus should have similar numbers of chemoreceptive sensilla and/or similar sensitivities of olfactory receptor cells to F1 sylvatic insects. Our results confirm that both populations have similar numbers of sensilla. Electrophysiological recordings of single chemoreceptive antennal sensilla are necessary in both populations to establish the threshold responses of different olfactory cells.

Euryphagic behaviour allows $R$. prolixus to adapt to new environmental conditions by allowing them to feed on different sources of blood (hosts). This feature not only facilitates ecological success but it also is important from an epidemiological point of view because it could lead to an increase in domiciliation of this species. The targeted reduction, especially in the pedicelum (Table), produced a reduction specifically in the BRs in $R$. prolixus (Catalá 1997), but the chemoreceptive sensilla remained constant even after 30 years of rearing under laboratory conditions.

\section{ACKNOWLEDGEMENTS}

To Maria Cristina Carrasquilla, for assistance with antenna preparations and sensilla identification, to Lorena Gonzalez, Isabel Meister and Paola Castillo, for their collaboration, and to Dr Alvaro Moncayo and to referees, for a critical revision of the manuscript and helpful suggestions.

\section{REFERENCES}

Altner H, Prillinger L 1980. Ultra structure of invertebrate chemo-, thermo-, and hygroreceptors and its functional significance. Int Rev Cytol 67: 69-139.

Arroyo CM, Esteban L, Catalá S, Angulo VM 2007. Variación del fenotipo antenal de poblaciones del domicilio, peridomicilio y silvestres de Triatoma dimidiata (Hemiptera: Reduviidae) en Santander, Colombia. Biomedica 27 (Suppl. 1): 92-100.

Barrozo RB, Couton L, Lazzari CR, Insausti TC, Minoli SA, Fresquet N, Rospars JP, Anton S 2009. Antennal pathways in the central nervous system of a blood-sucking bug, Rhodnius prolixus. Arthropod Struct Dev 38: 101-110.

Carbajal de la Fuente AL, Catalá S 2002. Relationship between antennal sensilla pattern and habitat in six species of Triatominae. Mem Inst Oswaldo Cruz 97: 1121-1125. 
Carcavallo R, Galíndez I, Jurberg J, Lent H 1998. List of natural and experimental flagellate infections in several Triatominae species. In RU Carcavallo, I Galindez, J Jurberg, H Lent, Atlas of Chagas' disease vectors in the Americas, Fiocruz, Rio de Janeiro, p. 289-298.

Catalá S 1996. Sensilla associated with the rostrum of eight species of Triatominae. J Morphol 228: 195-201.

Catalá S, Schofield C 1994. Antennal sensilla of Rhodnius. J Morphol 219: 193-203.

Catalá SS 1997. Antennal sensilla of Triatominae (Hemiptera: Reduviidae). A comparative study of five genera. Int J Insect Morphol Embryol 26: 67-73.

Catalá SS 1998. Antennae and rostrum. In RU Carcavallo, I Galindez, J Jurberg, H Lent. Atlas of Chagas' disease vectors in the Americas, Fiocruz, Rio de Janeiro, p. 74-83.

Catalá SS, Maida DM, Caro-Riaño H, Jaramillo N, Moreno J 2004. Changes associated with laboratory rearing in antennal sensilla patterns of Triatoma infestans, Rhodnius prolixus, and Rhodnius pallescens (Hemiptera, Reduviidae, Triatominae). Mem Inst Oswaldo Cruz 99: 25-30.

Dujardin JP 1998. Population genetics and the natural history of domestication in Triatominae. Mem Inst Oswaldo Cruz 93 (Suppl. II): 34-36.

Dujardin JP, Steindel M, Chavez T, Machane M, Schofield CJ 1999. Changes in the sexual dimorphism of Triatominae in the transition from natural to artificial habitats. Mem Inst Oswaldo Cruz 94: 565-569.

Enserink M 2002. What mosquitoes want: secrets of host attraction. Science 298: 90-92.

Esteban L, Angulo VM, Feliciangeli MD, Catalá S 2005. Analysis of antennal sensilla patterns of Rhodnius prolixus from Colombia and Venezuela. Mem Inst Oswaldo Cruz 100: 909-914.

Gracco M, Catalá S 2000. Inter-specific and developmental differences on the array of antennal chemoreceptors in four species of Triatominae (Hemiptera: Reduviidae). Mem Inst Oswaldo Cruz 95: 67-74.

Guerenstein PG, Lazzari CR 2009. Host-seeking: how triatomines acquire and make use of information to find blood. Acta Trop 110: $148-158$.

Guhl F, Aguilera G, Pinto N, Vergara D 2007. Actualización de la distribución geográfica y eco epidemiología de la fauna de triatominos (Reduviidae: Triatominae) en Colombia. Biomedica 27 (Suppl. 1): 143-162.

Jaramillo N, Castillo D, Wolff ME 2002. Geometric morphometric differences between Panstrongylus geniculatus from field and laboratory. Mem Inst Oswaldo Cruz 97: 667-673.

Leal WS 2005. Pheromone reception. Top Curr Chem 240: 1-36.

Lent H, Wygodzinsky P 1979. Revision of the Triatominae (Hemiptera, Reduviidae), and their significance as vectors of Chagas' disease. Bull Am Mus Nat Hist 163: 123-520.
López DC, Jaramillo C, Guhl F 2007. Estructura poblacional y variabilidad genética de Rhodnius prolixus (Hemiptera: Reduviidae) procedente de diferentes áreas geográficas de Colombia. Biomedica 27 (Suppl. 1): 28-39.

Mayer MS 1968. Response of single olfactory cell of Triatoma infestans to human breath. Nature 220: 924-925.

Moncayo A, Ortiz MI 2006. An update on Chagas disease (human American trypanosomiasis). Ann Trop Med Parasitol 100: 1-15.

Nicolaides N 1974. Skin lipids: their biochemical uniqueness. Science 186: $19-26$.

Ortiz M, Molina J 2010. Preliminary evidence of Rhodnius prolixus (Hemiptera: Triatominae) attraction to human skin odours extracts. Acta Trop 113: 174-179.

Pennington P, Beard CB, Anderson J 2005. Care, maintenance, and handling of infected triatomines. In WC Marquardt, Biology of disease vectors, Elsevier Academic Press, Amsterdam, p. 717-725.

Pitts RJ, Zwiebel L 2006. Antennal sensilla of two female anopheline sibling species with differing host ranges. Malar J 5: 26.

R Development Core Team 2006. R: A Language and Environment for Statistical Computing. R Foundation for Statistical Computing, Vienna, Austria. Available from: R-project.org.

Schofield CJ, Galvao C 2009. Classification, evolution, and species groups within the Triatominae. Acta Trop 110: 88-100.

Takken W, Knols BGJ 1999. Odor-mediated behaviour of afro tropical malaria mosquitoes. Annu Rev Entomol 44: 131-157.

TDR - Special Programme for Research and Training in Tropical Diseases 2009. Epidemiology of Chagas: past and present. In F Guhl, JK Lazdins-Helds, Grupo de trabajo cientifico. Reporte sobre la enfermedad de Chagas, TDR/World Health Organization, Ginebra, p. 1-3.

van den Broek IVF, den Otter CJ 1999. Olfactory sensitivities of mosquitoes with different host preferences (Anopheles gambiae s.s., An. arabiensis, An. quadirannulatus, An. m. atroparvus) to synthetic host odours. J Insect Physiol 45: 1001-1010.

Verhulst N, Beijleveld H, Knols BGJ, Takken W, Schraa G, Bouwmeester HJ, Smallegange RC 2009. Cultured skin microbiota attracts malaria mosquitoes. Malar J 8: 302.

Villela MM, Catalá S, Juberg J, Silva IG, Dias JCP 2005. Patterns of antenal sensilla of Panstrongylus megistus from three Brazilian states. Mem Inst Oswaldo Cruz 100: 699-702.

Zar JH 1999. Biostatistical analysis, Prentice Hall, New Jersey, $663 \mathrm{pp}$.

Zeledón R, Rabinovich JE 1981. Chagas' disease: an ecological appraisal with special emphasis on its insect vectors. Annu Rev Entomol 26: 101-133. 